DOI: $10.17805 / g g z .2017 .5 .3$

\title{
Синтез данных об эффективности принятых инициатив в образовании
}

\author{
ВАЛ. А. ЛУКОВ \\ МОСКОВСКИЙ ГУМАНИТАРНЫЙ УНИВЕРСИТЕТ, \\ Э. К. ПОГОРСКИЙ \\ ДАРЕМСКИЙ УНИВЕРСИТЕТ (ВЕЛИКОБРИТАНИџ)
}

В данной статье предлагается мнение, согласно которому, учет тезаурусного подхода и выделяемой им в тезаурусах культурной картины мира делает возможным сбор и синтез данных о факторах, влияющих на поведение людей, посредством компьютерных программ и алгоритмов. Разработка данных программ представляется особенно важной для улучшения освоения образовательных программ учащимися и внедрения лучших практик образовательными учреждениями.

Ключевые слова: система образования; синтез; искусственный интеллект; культурная картина мира; онлайн-курсы; тезаурусный подход

\section{Synthesis of Data on the Efficiency of Adopted Initiatives in Education}

\author{
VAL. A. LUKOV \\ MOSCOW UNIVERSITY FOR THE HUMANITIES, \\ E. K. POGORSKIY \\ DURHAM UNIVERSITY (UK)
}

This article proposes a view that taking into account the thesaurus approach and a cultural worldview that can be revealed by this approach in thesauri can be used for collecting and synthesis of data on factors, which have an influence on people's behaviour by algorithms and computer programs. The development of such programs is considered to be very important for improving educational programmes and exchanging the best practices of educational innovations between educators and policymakers.

Keywords: education system; synthesis; artificial intelligence; cultural worldview; online courses; thesaurus approach

В основе тезауруса субъекта, согласно тезаурусному подходу (Иуков В., Ауков Вл., 2014), лежит культурная картина мира. Эта идея уже не раз показывалась на философско-социологическом уровне (Кузнецова, 2012; Погорский, 2012а). Ее некоторые черты представлены как культурные константы в национальных культурах столь определенно, что выступают в синтезирующей функции для целых народов и даже культурных регионов. Такова, например, встреча Нового года. Модель этой встречи в английском и русском вариантах во многом схожа: время прихода Нового года и ухода предыдущего, новогодняя елка, праздничное настроение, подарки и т. А. На английскую модель большое влияние оказывает то, что 25 декабря различные ветви христианской церкви отмечают Рождество как праздник прежде всего семейный с большим числом традиционных символов (рождественский гусь, рождественские песнопения, нерабочий день и т. д.). Различие в календаре с Православной церковью и атеистический период в новейшей истории сказывается в том, что в российской традиции Новый год празднуется с чертами европейского Рождества. В картине мира субъекта немного таких синтетических итогов культурного развития, переведенных 
на нижние уровни (вплоть до индивидуального тезауруса личности) субъектной организации гуманитарного знания. Но они показательны именно как модели, актуализирующиеся регулярно. В большинстве случаев элементы культурной картины мира не заметны на поверхности, их надо выделить и выяснить их назначение. Традиционный подход в социологии основывается на частотности проявления тех или иных элементов (а они выступают чаще всего как реакция отделенных от других объектов анализа - например, в анкетном опросе - на высказывания, слова, отобранные исследователем с учетом его тезауруса) и не учитывает связи тезаурусов близких людей (родственников, друзей и т. А.), а также целостности тезаурусов, включающей, помимо прочего, сосуществование противоречащих утверждений у их (тезаурусов) носителей. Такой подход при заметных успехах в технологизации сбора и анализа данных в конце XX - начале XXI в. в принципе не синтетичен и не способен дать синтетического представления о смещениях в культурных картинах мира, как бы ни развивалась методика и техника исследований на базе новейших межличностных и других информационных коммуникаций.

Аелая детализацию картины мира в целях ее операционализации для эмпирических исследований (Погорский, 2012b), мы высказали предположение, что самую картину мира можно замерять с помощью электронных средств. Здесь, как кажется, возможно более обоснованное понимание синтетичности тезауруса и соответствующих способов измерения ядра тезауруса, каковым выступает культурная картина мира. Определенную продвинутость в этом направлении может дать, в частности, применение электронных средств для сбора данных об участниках образовательного процесса. Например, применяя расширение для браузера, которое позволяет захватывать данные о посещенных веб-сайтах пользователем, отправлять уведомления и пробовать изменить поведение с помощью этих уведомлений. Таким образом, можно рекомендовать пользователю вместо проведения времени в социальных сетях зайти на страницу онлайн-курса и продолжить заниматься. Это самое простое изменение означает, тем не менее, определенный выбор, но сделанный или несделанный выбор зависит от тезауруса и его ядра - картины мира.

Аанные, собранные с помощью электронных средств, например, как это было показано на приведенном выше примере, могут показать какие факторы оказывают эффект на принятие решений. Например, это применимо в сфере образования, в частности, к онлайн-курсам, которые получили широкое распространение на протяжении последних нескольких лет. По мере того, как такие курсы становятся привычными, их выбор все меньше опирается на новизну выбора. Иными словами, на выбор и продолжение обучения влияют факторы, нередко не осознаваемые носителями тезаурусов, но вычисляемые искусственным интеллектом (т. е. соответствующими цифровыми алгоритмами). Подобные цифровые системы, в частности, способны показать, есть ли у студента онлайн-курса определенные свойства личности, например, недостаток самоконтроля. Они позволяют установить, могут ли посещенные сайты и последовательность их посещения рассказать что-то о характеристиках человека. Многими университетами уже осуществляется сбор и анализ информации о взаимодействии обучающихся с онлайн-системами, такими как Moodle, Blackboard, образовательными онлайн-платформами, например, Coursera, FutureLearn, EdX (Siemens, Baker, 2012). Становится возможным анализ обучающихся через активность в веб-браузере и посещенные сайты (Pogorskiy, 2017), информации из окружающих физических объектов, либо устройств, подключенных к интернету (Blikstein, Worsley, 2016). Собран- 
ные данные и результаты их анализа могут быть организованы в виде тезаурусной сферы обучающегося, которая используется в последующем процессе обучения.

Но не только в этой достаточно узкой сфере ожидаются полезные результаты. Предварительный анализ важен, например, для совершенствования процедуры принятия законопроектов и анализа работы принятых законов. Пилотные исследования эффективности перед принятием законопроектов достаточно утвердились в практике работы законодательных органов, как и последующий анализ әффекта от реализации того или иного закона. Но эта практика относительно недавняя (в России - примерно с конца 1980-х годов), и в ней остается очень сильным субъективный момент. Региональная составляющая по существу не дает возможности опереться на данные исследований, которые получены в другом регионе. Аоверие к данным остается общей проблемой.

То же относится и к управлению крупными системами, где велика роль экспертного знания, в частности, системой образования. В этой сфере есть, как показано выше, подвижки в отношении тех форм, которые изначально задумывались как дистанционные и передаваемые пользователям с помощью цифровых программ. Нам представляется, что применение электронных баз знаний представляет собой перспективное направление, для образовательной практики, накопленной образовательными системами, вузами, различными центрами и фондами. Например, в Аареме есть Centre for Evaluation and Monitoring (www.cem.org/about-us), собирающий данные об обучении в детском и школьном возрасте, где в том числе применяют некоторые техники из машинного обучения, чтобы распознать лучшие практики. Одно из перспективных направлений этой работы связано с изменением поведения обучающихся. Так, в Центре по исследованию изменений поведения Университетского колледжа начал осуществляться проект Human Behaviour Change Project (www.ucl.ac.uk/humanbehaviour-change/about), цель которого узнать, какие вмешательства по изменению поведения работают и насколько хорошо, для кого и в каком контексте. Авторы проекта свои разработки связывают в основном с областью здравоохранения. Их, например, интересует, в каких случаях человек выберет яблоко вместо сникерса, пойдет в спортзал вместо бара, выберет 10-минутную прогулку вместо курения сигареты и т. д. Участники проекта планируют с помощью алгоритмов проиндексировать мировую научную литературу с результатами исследований о вмешательствах по изменению поведения людей (behaviour change interventions) и на основе этой базы знаний генерировать прогнозы с рекомендациями о том, какие вмешательства могут иметь наибольший эффект в каждом конкретном случае. Этот подход может быть также распространен и на другие сферы, в частности, на систему образования. В этом случае могут быть получены объективные (т. е. не осознаваемые обучающимся, его родителями и т. А.) данные, при каких вмешательствах данный (а не условный) школьник выберет для поступления специальность врача вместо экономиста и т. А.

Перенося этот опыт на Россию, можно было бы попробовать инициировать синтез педагогической практики, накопленной в России, и, например, отбор наиболее успешного опыта или инициатив в регионах или вузах и его рекомендация к тиражированию в масштабах страны. Это остается одним из слабых мест в российской системе образования, и субъективизм при определении исполнителей такого рода проектов, остается их уязвимым местом. Искусственный интеллект в этом направлении кажется скорее метафорой, между тем мировой опыт все больше и больше опирается на него, вступая или уже вступив в информационное общество, не повторяющего свойства 
предыдущих общественно-экономических формаций (Ауков, Погорский, 2014). Синтез данных об эффективности принятых инициатив в образовании опирается на культурную картину мира, присущую тезаурусам учащихся очень рано и определяющую их (тезаурусов) несущие черты при столкновении с хорошо отработанной системой образования. В тезаурусах при таком столкновении не может не происходить перемен, но культурная картина мира при ее способности сочетать несочетаемое остается в основном стабильной и мало подверженной переменам, что и позволяет опираться на нее при решении новых задач образования.

\section{СПИСОК АИТЕРАТУРЫ}

Кузнецова, Т. Ф. (2012) Культурная картина мира: теоретические проблемы : науч. монография. М. : ГИТР. 250 с.

Ауков, В. А., Ауков, Вл. А. (2014) Методология тезаурусного подхода: стратегия понимания // Знание. Понимание. Умение. № 1. С. 18-35.

Ауков, В. А., Погорский, Э. К. (2014) Информационное общество и молодежь : науч. монография. М. : ИзА-во Моск. гуманит. ун-та. 160 с.

Погорский, Э. К. (2012а) Картина мира // Знание. Понимание. Умение. № 4. С. 322-323.

Погорский, Э. К. (2012b) Инновационность молодежи как источник социокультурных изменений на этапе становления информационного общества : автореф. дис. ... канд. филос. наук. M. 26 c.

Blikstein, P., Worsley, M. A. B. (2016) Multimodal learning analytics and education data mining?: using computational technologies to measure complex learning tasks // The Journal of Learning Analytics. Vol. 3. No. 2. P. 220-238.

Pogorskiy, E. (2017) Digital behaviour change interventions through a web browser extension to improve learners' retention // 3rd UCL Centre for Behaviour Change Digital Health Conference 2017: Harnessing Digital Technology for Behaviour Change, London, United Kingdom, February 22-23, 2017. : conference abstract. DOI: 10.3389/conf.FPUBH.2017.03.00014

Siemens, G., Baker, R. S. J. d. (2012) Learning analytics and educational data mining: Towards communication and collaboration // LAK'12 : Proceedings of the 2nd International Conference on Learning Analytics and Knowledge. Vancouver, British Columbia, Canada, April 29 - May 02, 2012. P. 252-254. DOI: $10.1145 / 2330601.2330661$

Ауков Валерий Андреевич - доктор философских наук, профессор, директор Института фундаментальных и прикладных исследований Московского гуманитарного университета. Эл. aApec: v-lukov@list.ru

Погорский Эдуард Константинович - кандидат философских наук, Ааремский университет (Великобритания). Эл. адрес: eduard.pogorskiy@durham.ac.uk

Lukov Valery Andreevich, Doctor of Philosophy, Professor; Director, Institute of Fundamental and Applied Studies, Moscow University for the Humanities. E-mail: v-lukov@list.ru

Pogorskiy Eduard Konstantinovich, Candidate of Philosophy (PhD), Durham University (UK). E-mail: eduard.pogorskiy@durham.ac.uk

\section{Аля изтирования:}

Ауков В. А., Погорский Э. К. Синтез данных об эффективности принятых инициатив в образовании [Электронный ресурс] // Горизонты гуманитарного знания. 2017. №5. URL: http:// journals.mosgu.ru/ggz/article/view/600 (дата обращения: дА.мм.гггг.). DOI: 10.17805/ggz.2017.5.3 